\title{
Characteristics and Behavior of Voltage Transient and Inrush Current due to Switching Capacitor Bank
}

\author{
S. Ananwattanaporn ${ }^{\text {a, }}$, T. Patcharoen ${ }^{\text {a }}$, S. Yoomak ${ }^{\text {a }}$, A. Ngaopitakkul ${ }^{\text {a }}$, and C. Pothisarn ${ }^{\text {a }}$ \\ ${ }^{a}$ Faculty of Engineering, King Mongkut's Institute of Technology Ladkrabang, Bangkok, 10520, Thailand \\ *Corresponding Author: san ti ton@hotmail.com, knatthap@kmitl.ac.th
}

\begin{abstract}
Capacitor bank system in substation has been a topic of interest in these past few years because of its advantage on system. This paper presents a study on transient signal that occurs when switching capacitor is integrated into the system. The method is based on building a capacitor bank switching experimental setup, which is downscaled from Electricity Generating Authority of Thailand (EGAT) at NongChok substation. This experimental setup is aimed to investigate transient signal in capacitor bank switching that has impact on the power system, such as inrush current and voltage transient. The result shows that switching transient causes an inrush current with high amplitude compared to nominal current. Moreover, an inductor installed in the system can limit inrush current; when inductor size is increased, inrush current will be decreased.
\end{abstract}

Keywords: Inrush current, switching capacitor bank, transient.

\section{Introduction}

In recent year, topic of interest in substation research is to reduce loss and increase power efficiency in distribution system. One of the systems that can solve this issue is capacitor bank system. Capacitor bank consists of small capacitor unit connected in series and parallel inside enclosed bank. These banks provide reactive power to the system to compensate with inductive loads connected. High power capacitor bank in substation can make system stabilized when voltage drop occurs due to peak period. Other advantages of adding capacitor bank in the system are loss reduction while power is transmitted between regions and power capacity increasing in transmission system $^{(1)}$.
Switching capacitor bank has several effects on power quality that needs to be considered. First one is overvoltage transient at switching and nearby bank. Second is current transient or inrush current. This transient occurs when capacitor bank is energized, then causing a current signal with high amplitude and frequency. Last one is harmonics problem because switching capacitor bank can amplify amplitude and frequency of harmonic signal. These power quality problems can damage capacitor banks, control equipment in substation or entire power system. System reliability cannot be archived with problem aforementioned. Hence, the study and analysis on the transient characteristics must be carried out to determine whether the system can handle these power quality problems before installing the capacitor bank in the substation.

Researches and studies on capacitor bank system from many regions have been reviewed. As shown in (1-3), the benefit from installing capacitor bank in transmission system has been evaluated. Capacitor system can increase power capacity and improve reliability in the region. In (4), capacitor bank in distribution network can reduce harmonics and also increase power factor in the system. Another research in (5) is a study to determine the optimal location of capacitor bank to reduce power loss in distribution system. Literature about switching transient effect and protection has been also reviewed as in (6-15). These researches reveal impact of switching transient to protection system and present an optimal design for protection system in high power capacitor bank ${ }^{(8-11)}$.

The purpose of this paper is to study and present impact of switching transient generated from capacitor bank. Main parameters such as voltage and current are observed during switching time. The system in this study is a modeling of EGAT at NongChok substation. Two configurations have been studied in this paper. One with 
inductor connected in series with capacitor bank and one without inductor. These two set data are compared to evaluate the effect of inductor installed in capacitor bank system.

\section{Experimental Setup}

Capacitor bank system in this study is EGAT NongChok substation at voltage level of $115 \mathrm{kV}$. Substation system consists of 3 steps of capacitor bank with reactive power of 48 MVar in each step. This experimental setup model is downscaled from $115 \mathrm{kV}$ to $415 \mathrm{~V}$ in laboratory. The process is using per unit calculation to determine size of capacitor and other devices or equipment in the system.
From calculation, capacitor bank used in the experimental setup has reactive power of 5 MVar in each step with ungrounded wye for internal connection. Single line diagram of experimental setup is shown in Fig. 1. The power supply of the system is from laboratory at voltage level of $380 \mathrm{~V}$ before connecting to variable voltage transformer. Voltage output supplying system will be at 415 $\mathrm{V}$; this will supply capacitor and other equipment in experimental setup. Switching Capacitor in each step using contactor $\mathrm{K} 1, \mathrm{~K} 2$, and $\mathrm{K} 3$ is controlled by power factor controller. For measurement, current is measured at phase A using current probe clamping after main circuit breaker and voltage is measured at busbar for three phases as shown in Fig. 1.

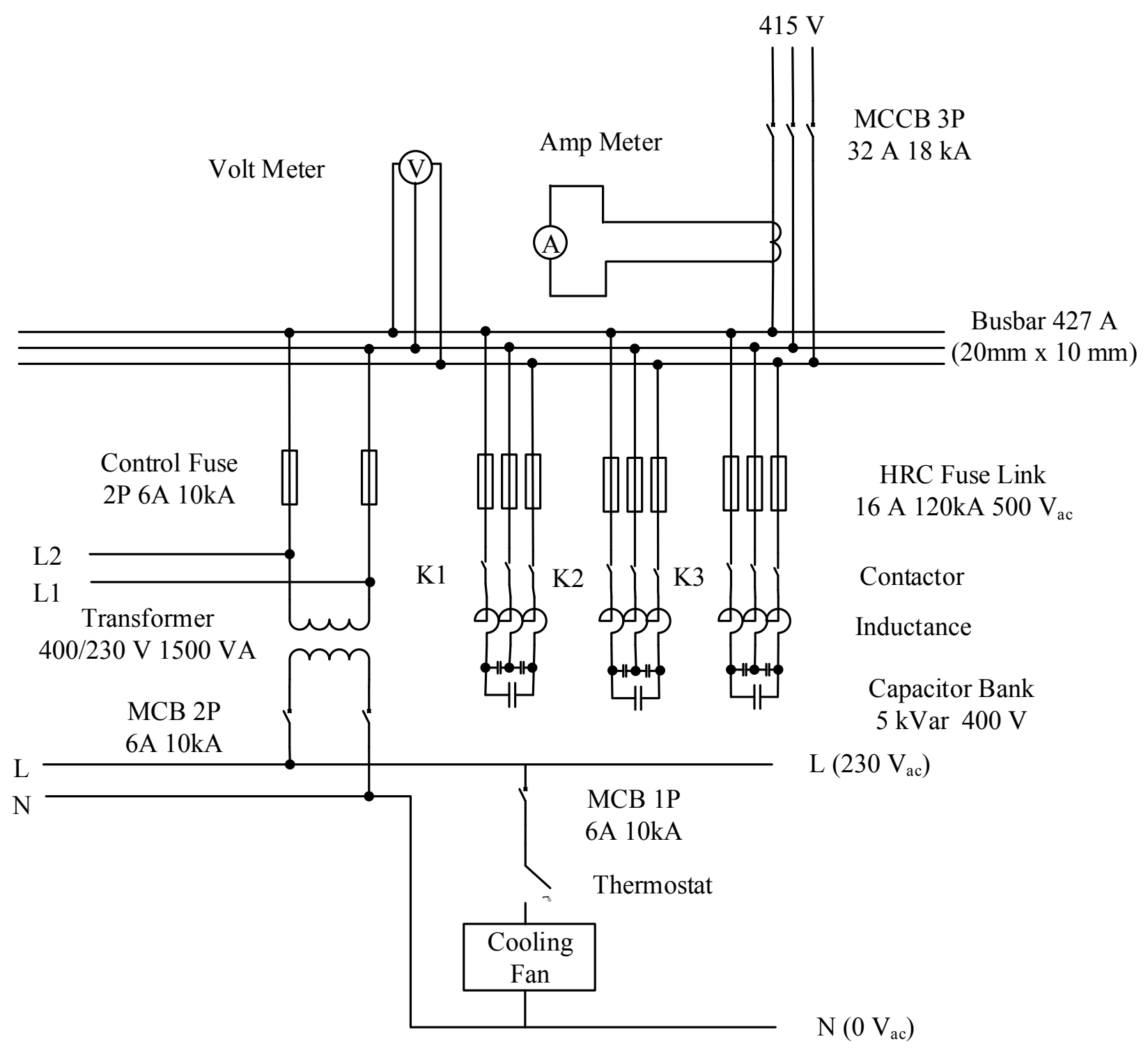

Fig. 1. Single line diagram of experimental setup 


\section{Voltage Transient and Inrush Current}

In this study, after measuring voltage and current from the system in normal case; to evaluate the effect of switching transient, size of inductor is changed. From single line diagram in Fig. 1, normal wire after contactor is changed to inductor sizes of $2,4,6$, and $8 \mu \mathrm{H}$. Waveform capture from instrument at switching time is shown in Fig. 2. Fig. 2(a), (c), (e), (g), and (i) are voltage waveforms at first step switching time whereas Fig. 2(b), (d,), (f), (h), and (j) are current waveforms at first step switching time. From the waveforms, they show that switching capacitor bank causes voltage transient and inrush current in the system.

\subsection{Voltage Transient}

From voltage waveform, it reveals that voltage transient occurs when capacitor bank is energized due to contactor connected capacitor bank into the system. Voltage transient caused by switching capacitor bank has slight change in magnitude compared with nominal case, and transient signal enters in steady state in short period of time. Voltage data obtained from the system are shown in Table 1. This table shows that size of inductor and step of switching capacitor bank do not affect voltage transient characteristics. The one that has effects is angle at switching time, which causes a varying in voltage amplitude.

\subsection{Inrush Current}

Current waveform captured from the system shows that at switching time, occurred inrush current has greater magnitude than nominal current. This happened in short amount of time. Current measured from the system is also shown in Table 2. This current shows that more inductor size is increased more the peak of inrush current is decreased. This trend can be applied to each step of capacitor bank. Another factor that has the effect on inrush current is capacitor step. When the step is increased, the amplitude of inrush current is also increased; this is because the current issued from source already energizes capacitor bank. The inrush current measured from system can be plotted as illustrated in Fig. 3. The $\mathrm{x}$-axis corresponds to inductor size and the $y$-axis corresponds to current amplitude. This figure shows the trend of inrush current with different sizes of inductor connected in series to capacitor bank. Different angles of switching could create different current values as shown in step 2 of system with inductor of $2 \mu \mathrm{H}$.

Table 1. Three-phase voltage transient at capacitor bank switching time with various sizes of inductor

\begin{tabular}{|c|c|c|c|c|c|c|c|c|c|c|c|c|c|c|c|}
\hline \multirow{3}{*}{$\begin{array}{c}\text { Capacitor } \\
\text { Step }\end{array}$} & \multicolumn{15}{|c|}{ Voltage (V) } \\
\hline & \multicolumn{3}{|c|}{ Without inductor } & \multicolumn{3}{|c|}{ Inductor of $2 \mu \mathrm{H}$} & \multicolumn{3}{|c|}{ Inductor of $4 \mu \mathrm{H}$} & \multicolumn{3}{|c|}{ Inductor of $6 \mu \mathrm{H}$} & \multicolumn{3}{|c|}{ Inductor of $8 \mu \mathrm{H}$} \\
\hline & Phase A & Phase B & Phase C & Phase A & Phase B & Phase C & Phase A & Phase B & Phase C & Phase A & Phase B & Phase C & Phase A & Phase B & Phase C \\
\hline $\begin{array}{c}\text { Normal } \\
\text { case }\end{array}$ & 228.8 & 232.1 & 231.9 & 239.7 & 242.3 & 241.6 & 241.1 & 244.0 & 242.9 & 237.3 & 241.8 & 239.9 & 236.5 & 240.9 & 239.2 \\
\hline Step 1 & 229.6 & 232.4 & 232.2 & 240.1 & 242.7 & 242.1 & 241.6 & 244.5 & 24.4 & 237.7 & 242.2 & 240.2 & 236.9 & 241.2 & 239.6 \\
\hline Step 2 & 229.9 & 232.6 & 232.4 & 240.6 & 243.2 & 242.5 & 242.2 & 244.9 & 243.8 & 238.3 & 242.7 & 240.7 & 237.2 & 241.6 & 239.8 \\
\hline Step 3 & 229.9 & 232.7 & 232.4 & 240.9 & 243.5 & 242.8 & 242.6 & 245.3 & 244.2 & 238.6 & 242.9 & 240.9 & 237.6 & 241.9 & 240.2 \\
\hline
\end{tabular}

Table 2. Inrush current measured from capacitor bank system during switching time

\begin{tabular}{|c|c|c|c|c|c|}
\hline \multirow{2}{*}{ Capacitor Step } & \multicolumn{5}{|c|}{ Inrush Current (A) } \\
\cline { 2 - 6 } & Without inductor & Inductor of $2 \mu \mathrm{H}$ & Inductor of $4 \mu \mathrm{H}$ & Inductor of $6 \mu \mathrm{H}$ & Inductor of $8 \mu \mathrm{H}$ \\
\hline Step 1 & 120.2 & 81.6 & 81.4 & 78.6 & 66 \\
\hline Step 2 & 163.7 & 97.7 & 124.7 & 133.3 & 123.8 \\
\hline Step 3 & 185.6 & 179.5 & 149.3 & 149.3 & 135 \\
\hline
\end{tabular}




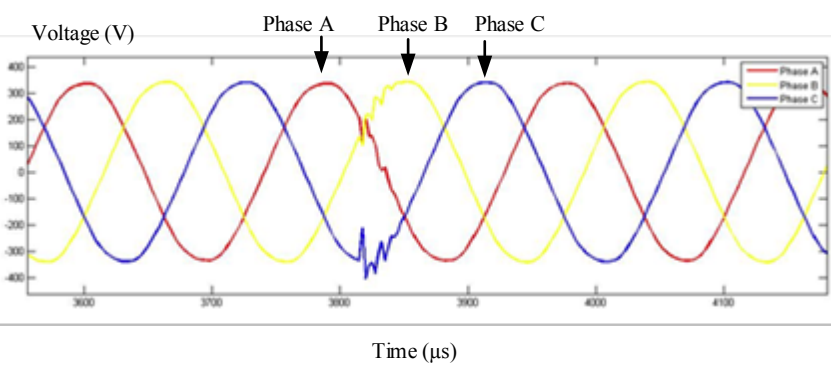

(a) Voltage waveform without inductor connected

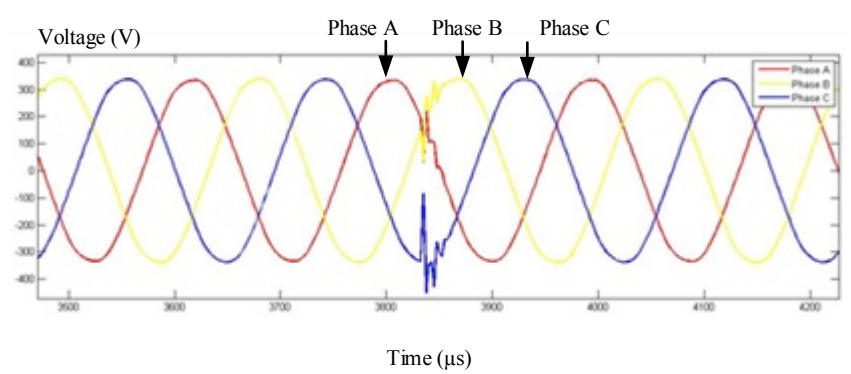

(c) Voltage waveform with $2 \mu \mathrm{H}$ inductor connected

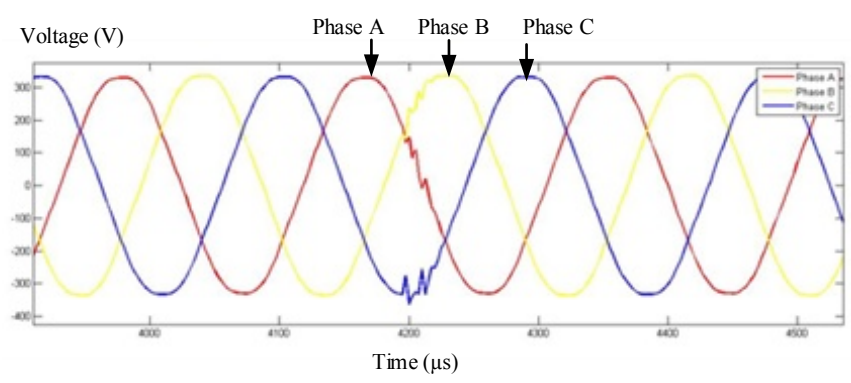

(e) Voltage waveform with $4 \mu \mathrm{H}$ inductor connected

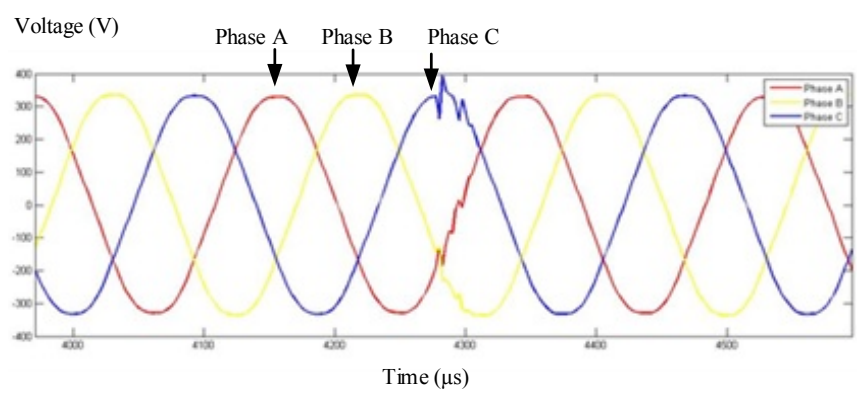

(g) Voltage waveform with $6 \mu \mathrm{H}$ inductor connected Voltage (V)

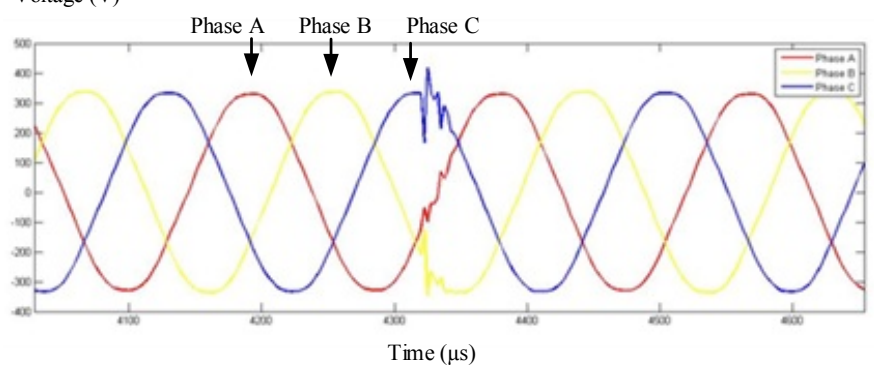

(i) Voltage waveform with $8 \mu \mathrm{H}$ inductor connected

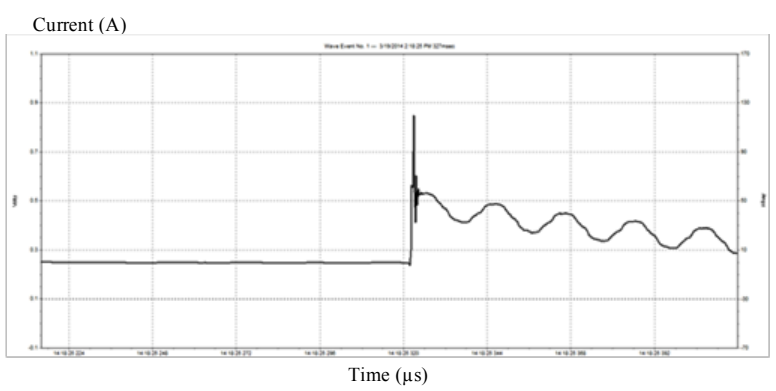

(b) Current waveform without inductor connected Current (A)

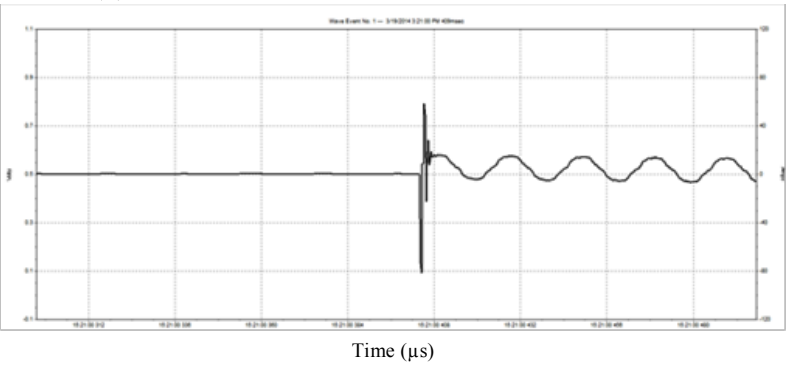

(d) Current waveform with $2 \mu \mathrm{H}$ inductor connected

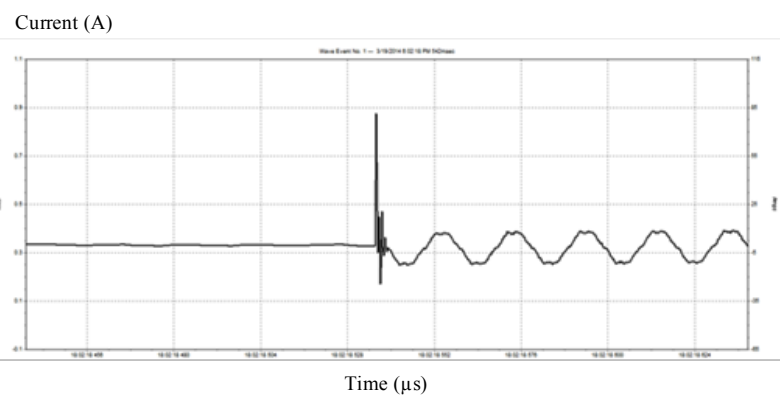

(f) Current waveform with $4 \mu \mathrm{H}$ inductor connected Current (A)

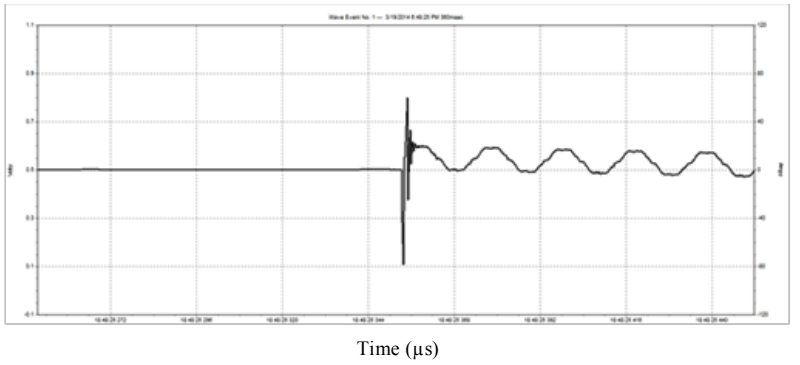

(h) Current waveform with $6 \mu \mathrm{H}$ inductor connected

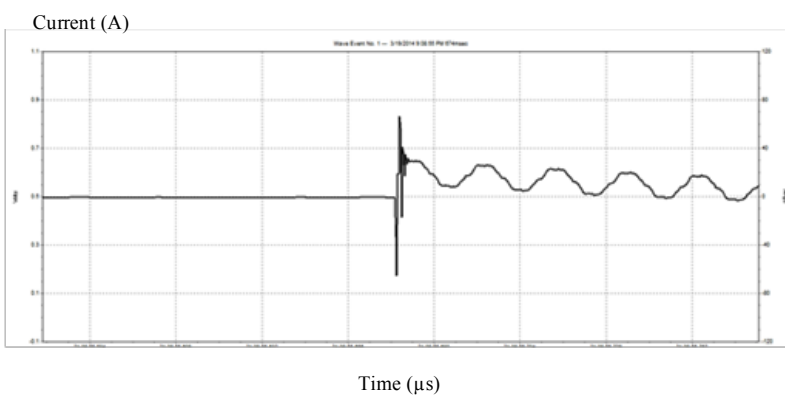

(j) Current waveform with $8 \mu \mathrm{H}$ inductor connected

Fig. 2. Voltage and current waveforms with various sizes of inductor connected 


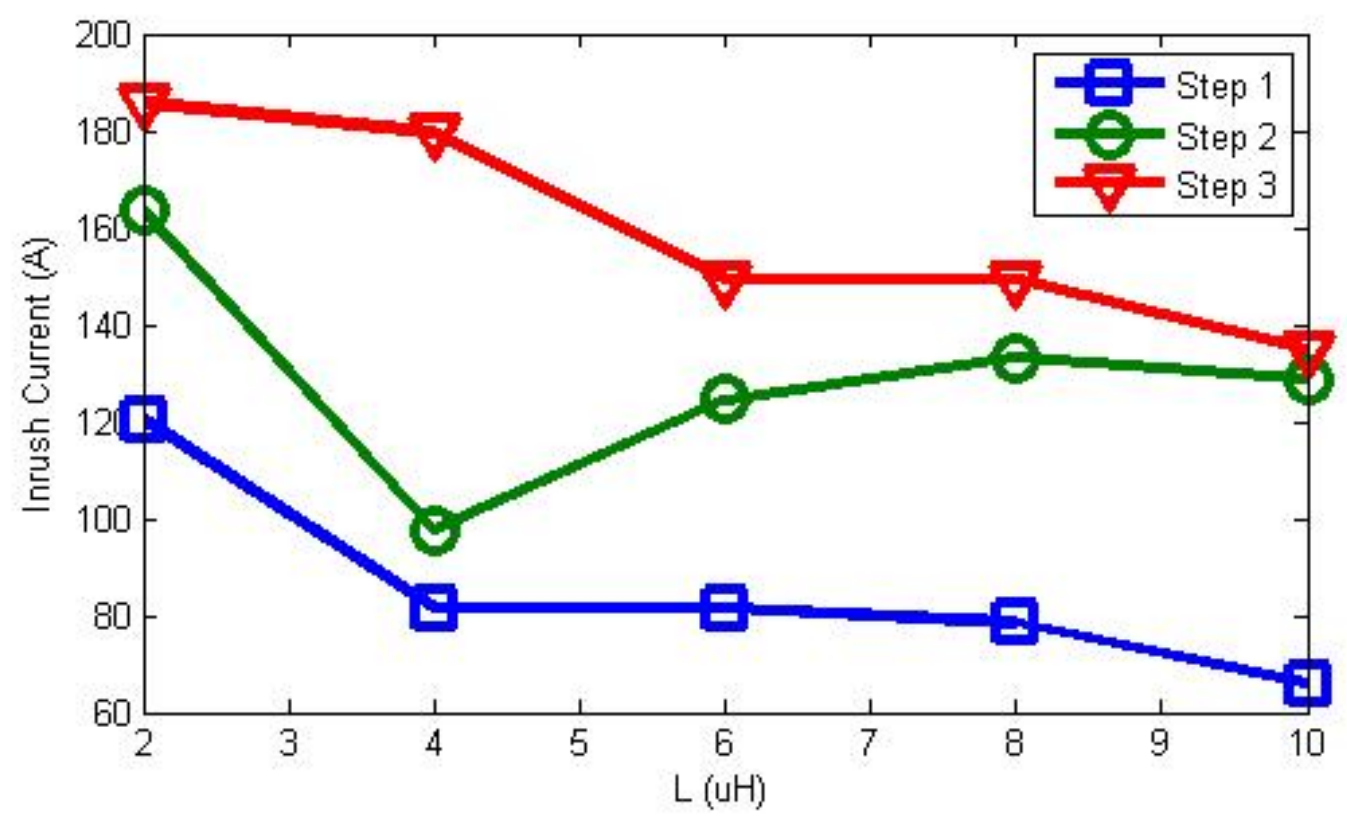

Fig. 3. Inrush current with different sizes of inductor for each capacitor step

\section{Conclusions}

In this paper, switching transient characteristics in substation capacitor bank system has been studied by focusing on voltage transient and inrush current occurred in the system. The different sizes of inductor were used in the system to discuss their effect on switching transient.

The results have illustrated that when capacitor bank was energized due to contactor connected switching capacitor into the system, it caused voltage transient and high inrush current in short amount of time. In the system with many steps of capacitor bank, the inrush current was increased when next step of capacitor bank was connected. This result also revealed that the series inductor could limit inrush current magnitude, but it had no effects on voltage transient. With the increase of inductor size, the inrush current amplitude has been significantly decreased. This can be applied to system protection in order to ensure reliability and stability of power system.

\section{Acknowledgment}

The authors wish to gratefully acknowledge financial support for this research from the King Mongkut's Institute of Technology Ladkrabang Research fund, Thailand.

\section{References}

(1) T. E. Grebe : "Application of distribution system capacitor banks and their impact on power quality", IEEE Transactions on Industry Applications, Vol. 32, No. 3, pp. 714-719, 1996.

(2) S. A. Ali : "Capacitor Banks Switching Transients in Power System", Energy Science and Technology Vol. 2, No. 2, pp. 62-73, 2011.

(3) T. Surawut, T. Surapong, C. Seksak, and J. Boonseang : "Transient Capacitor Switching for H.V. Substation due to Voltage Magnification", King Mongkut's Institute of Technology Ladkrabang Bachelor's Thesis, 1999.

(4) R. Grunbaum, G. Ingestrom, B. Ekehov, and R. Marais : "765kV Series Capacitors For Increasing Power Transmission Capacity To The Cape Region", IEEE Power Engineering Society Conference and Exposition in Africa (Power Africa), pp. 1-8, 2012.

(5) K. Tilakul, P. Buasri, A. Kaewrawang and J. Triyangkulsri : "Capacitor Location and Size Determination to Reduce Power Losses of a Distribution Feeder in Lao PDR", International Journal of Computer and Electrical Engineering, Vol. 4, No. 1, pp. 32-36, 2012.

(6) T. Manglani and Y. S. Shishodia : "A Survey of Optimal Capacitor Placement Techniques on Distribution Lines to Reduce Losses", International 
Journal of Recent Research and Review, Vol. 1, pp. $1-7,2005$.

(7) O. O. Stephen, L. Yanli, and S. Hui : “Application of Switched Capacitor Banks For Power Factor Improvement And Harmonics Reduction On The Nigerian Distribution Electric Network", International Journal of Electrical \& Computer Sciences IJECS-IJENS, Vol. 11, No. 6, pp. 58-68, 2011.

(8) A. Baloi, L. Kocewiak, C. L. Bak, and A. Pana : "Experimental Determination of Harmonic Conditions Amplification in a Distribution Network by Capacitor Bank Switching", 13th International Conference on Optimization of Electrical and Electronic Equipment (OPTIM), pp. 194-199, 2012.

(9) A. Baby, J. Thomas, and T. Joseph : "Analysis of Voltage Collapse in the Kerala Power Grids", International Conference on Computer Communication and Informatics (ICCCI), pp. 1-5, 2013.

(10)B. Kasztenny, J. Schaefer, and E. Clark : "Fundamentals of adaptive protection of large capacitor banks", Power Systems Conference: Advanced Metering, Protection, Control, Communication, and Distributed Resources, pp.154-186, 2007.
(11) Myeong-Hee Lee and Cha-Soo Park : "The Protection System Optimization of $154 \mathrm{kV}$ Shunt Capacitor Bank in Korea", Journal of International Council on Electrical Engineering, Vol. 3, No. 2, pp. 141-145.

(12) R. Frye, J. Hicks, and E. Price : “Achieving Optimum Capacitor Bank Protection and Control”, 65th Annual Conference for Protective Relay Engineers, pp. 410-424, 2012.

(13) G. Gopakumar, H. Van, B. A. Mork, and K. K. Mustaphi "Shunt Capacitor Bank Switching Transients a Tutorial and Case Study", Minnesota Power Systems Conference, No. 2-4, 1999.

(14)D. B. Mupparty : "Capacitor Switching Transient Modeling and Analysis on An Electrical Utility Distribution System Using SIMULINK Software", University of Kentucky Master's Thesis, 2011.

(15)T. Suwanasri, S. Wattanawongpitak, and C. Suwanasri : "Multi-step back-to-back capacitor bank switching in a $115 \mathrm{kV}$ substation", International Conference on Electrical Engineering/Electronics Computer Telecommunications and Information Technology (ECTI-CON), pp. 459-463, 2010. 